\title{
Dermoscopy of difficult-to-diagnose Melanomas
}

\author{
Chrysoula PAPAGEORGIOU, Demetrios IOANNIDES, Zoe APALLA, Efstratios VAKIRLIS, \\ Elisabeth LAZARIDOU, Eleni SOTIRIOU, Aimilios LALLAS ${ }^{1}$
}

${ }^{1}$ First Department of Dermatology, Aristotle University, Thessaloniki, Greece

*Correspondence: Lallas Aimilios, emlallas@gmail.com

DE GRUYTER

UDC 616.5-006.8-073/-076

\begin{abstract}
Dermoscopy is a non-invasive procedure that allows the evaluation of cutaneous lesions, and is considered to be a useful tool that improves the diagnostic accuracy of melanoma. Many dermoscopic criteria of melanoma have been established and several algorithms have been created for melanoma detection. However, the recognition of some melanomas remains challenging. Melanomas on specific body sites, melanomas in patients with multiple atypical moles, and nodular melanomas represent the most difficult-to-recognize melanoma subtypes, since they typically lack the "classic" melanoma-specific criteria. This paper provides an update on dermoscopy of difficult-to-diagnose melanomas by summarizing the newest data. Lastly, we highlight the importance of digital dermoscopy in the follow-up of melanocytic lesions for the detection of incipient melanomas while maintaining a low excision rate.
\end{abstract}

\section{Key words}

Dermoscopy; Melanoma; Diagnosis; Skin Neoplasms

$\mathrm{D}$ ermoscopy is a non-invasive diagnostic procedure that allows the visualization of structures located in the epidermis, dermoepidermal junction and papillary dermis, that normally cannot be seen with the naked eye (1). Dermoscopy was first introduced for diagnosis and evaluation of skin tumors and melanomas, and gradually has become a commonly used skin cancer screening tool. (2). Nowadays, digital dermoscopy follow-up has gained ground for the monitoring of patients especially those with multiple and atypical moles.

The traditional dermoscopic criteria of melanoma have been investigated and established in the context of superficial spreading melanoma (SSM). SSM is the most common and the easiest to recognize type of melanoma. However, it might be difficult to detect in early stages.

Dermoscopic features of SSM include atypical pigment network, irregular dots or globules, irregular streaks and regression structures (Figure 1) $(3,4)$. Asymmetric pigmentation pattern, asymmetric shape, irregular blotches, blue-white veil and a multicomponent global pattern can also be observed (4 - 6). An atypical vascular pattern of linear irregular vessels, dotted vessels, or milky-red areas are also a common finding $(4-6)$.

Sadayasu et al. suggested the presence of a sudden change of the intralesional color, from a blue-gray structureless area in the center to a peripheral lightbrown pigment network, as a diagnostic indicator of melanomas (3).

The aforementioned melanoma criteria have been tested in several studies and showed valid for melanoma diagnosis. Based on these criteria, several dermoscopic algorithms have been created (ABCD rule, 7-point checklist, Menzies method). However, melanomas on specific body sites, melanomas in patients with multiple atypical moles, and nodular melanomas often lack the "traditional" melanoma criteria, rendering their recognition particularly troublesome.

This paper aims to summarize recent advances on the dermoscopic patterns of difficult-to-diagnose melanomas.

\section{Acral melanoma}

Acral melanoma (AM) is considered to have poorer prognosis compared to other melanoma types. Therefore, its early detection is of utmost importance. 
Dermoscopy allows clinicians to detect morphological characteristics of melanomas that precede the appearance of clinical symptoms (7).

AM is dermoscopically characterized by a multicomponent pattern, a parallel ridge pattern, irregular diffuse pigmentation (also called blotches), milky-red areas, peripheral dots and globules, and an abrupt peripheral margin (Figure 2) (8). It has to be noted that, besides the dermoscopic patterns, clinicians should always take into account the maximum diameter of the acral lesions. Saida et al. and Braun et al. observed that lesions with a diameter $>7 \mathrm{~mm}$ and $>1 \mathrm{~cm}$, respectively, are more likely to be melanomas, regardless of dermoscopic characteristics $(9-11,8)$.

As for the subungual melanoma, dermoscopic criteria include light to dark brown coloration of the background, the lines are barely visible, brown to black longitudinal lines, the color, spacing and the width are irregular, parallelism and Hutchinson's sign (periungual pigmentation) (Figure 3) (12, 13).

Lallas et al. developed the BRAAFF scoring system for the detection of AM without nail-apparatus melanoma. The dermoscopic variables include four positive predictors (irregular blotches, parallel ridge pattern, asymmetry of structures, asymmetry of colors) and two negative predictors (parallel furrow pattern, fibrillary pattern). The authors highlighted that these variables should always be counted in the overall clinical context of the patient and recommend histopathological examination in equivocal cases (14).

\section{Mucosal melanoma}

Although dermoscopy is widely used in the diagnosis of pigmented and nonpigmented lesions of the skin, its role in the evaluation of pigmented mucosal lesions is not well established. The two largest studies referring to dermoscopy of pigmented mucosal lesions were conducted by Lin et al. (15) and the International Dermoscopy Society (IDS) (16), and included 40 and 140 pigmented mucosal cases, respectively, from lips, penis, vulva and other anogenital areas.

According to the results of the first study, asymmetry of structure, multiple colors, blue-white veil and irregular dots/globules are the commonest features in mucosal melanoma compared with the findings of benign lesions. In the second study, a combination of at least 1 of 3 colors (blue, gray or white) with structureless zones was shown to have a relatively high diagnostic accuracy when differentiating between benign and malignant lesions. Moreover, authors noted that multiple colors outmatch the multiple patterns. Finally, the presence of structureless parts and gray color may be indicative of early stages of mucosal melanomas (MM). On the contrary, multiple patterns and additional colors, especially blue or white, seem to be more indicative of late MM stages.

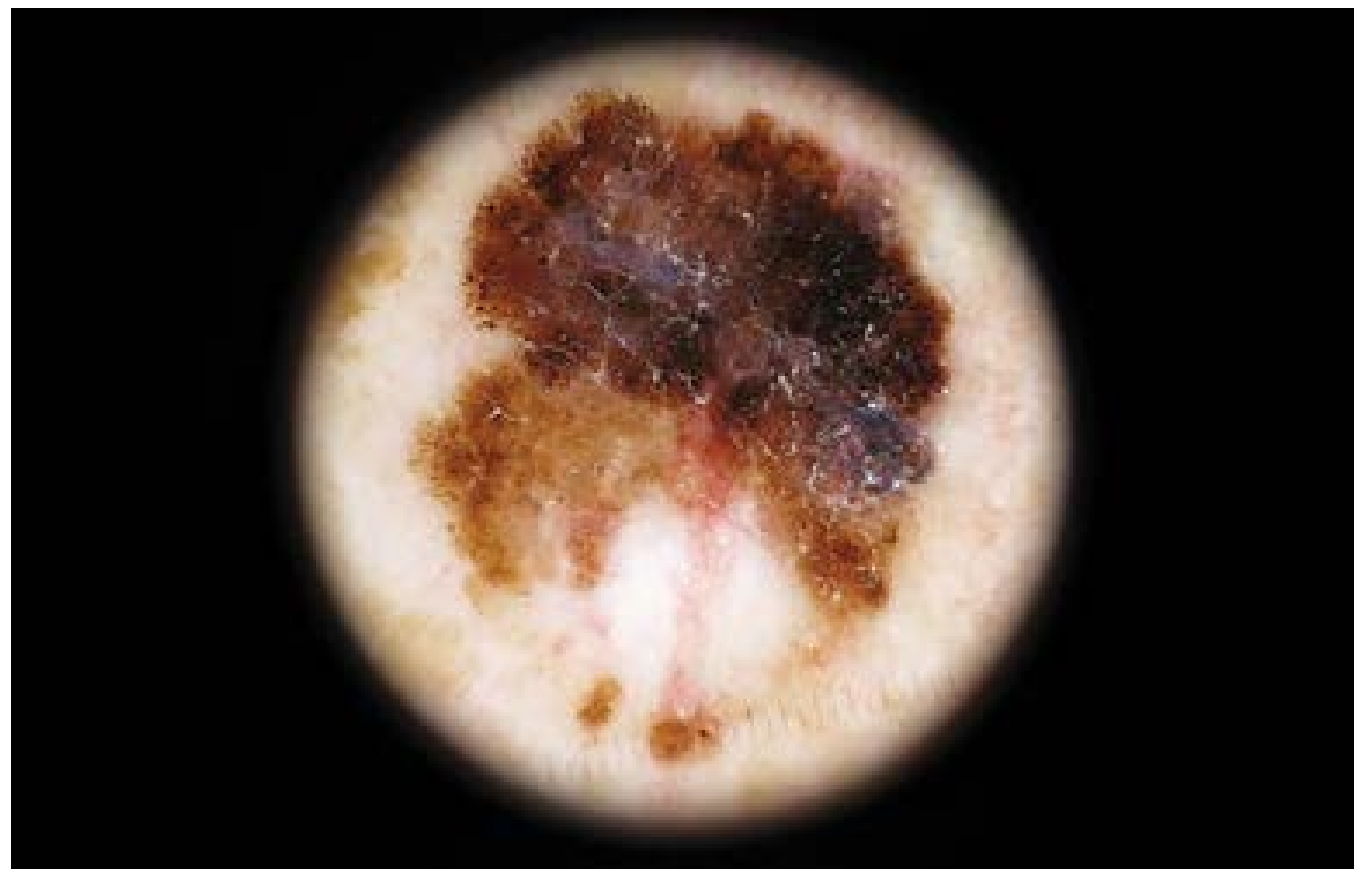

Figure 1. A typical superficial spreading melanoma dermoscopically displaying a multicomponent pattern consisting of irregular blotches, irregular dots or globules, irregular streaks and regression structures 


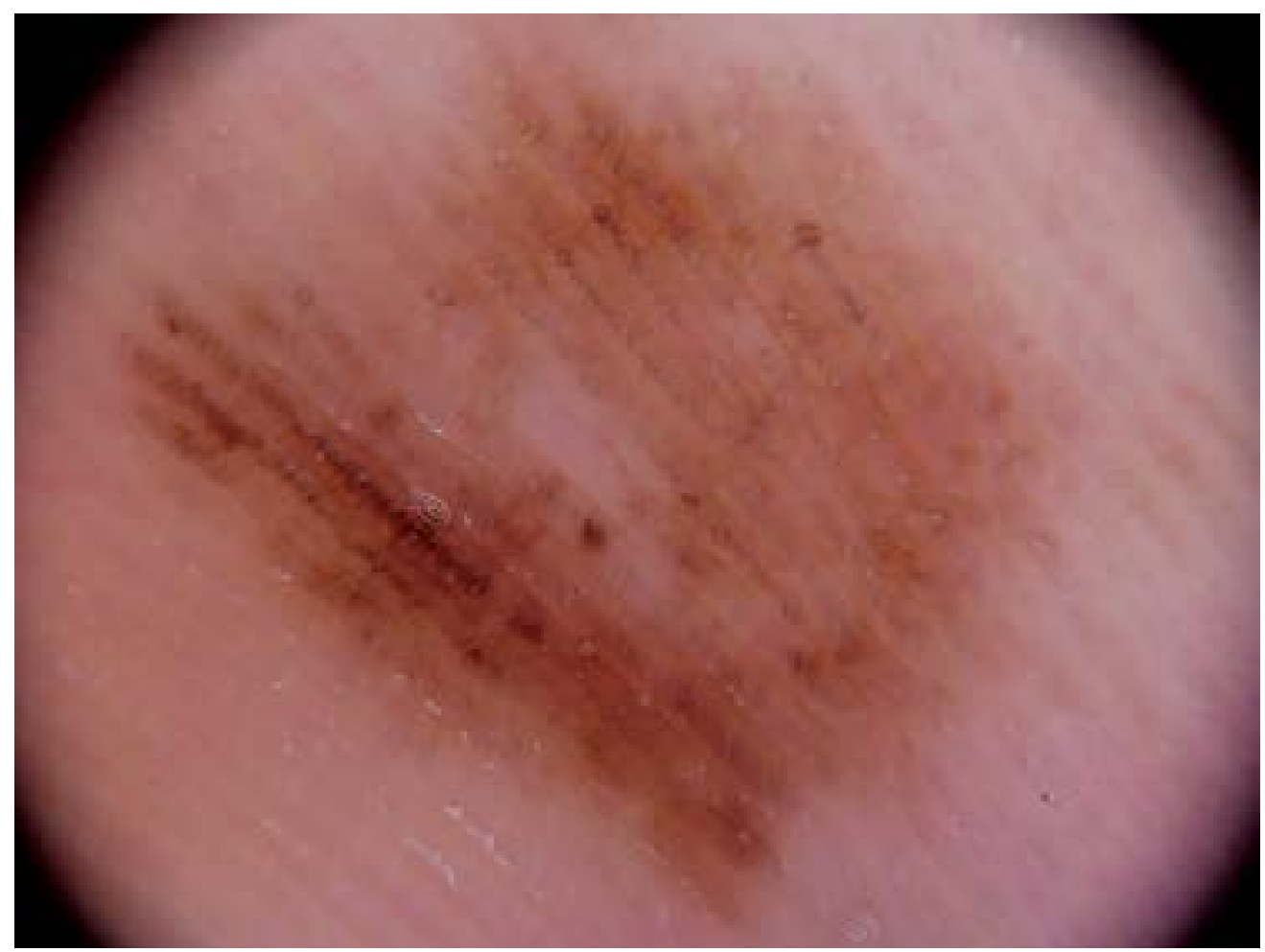

Figure 2. An acral melanoma dermoscopically typified by a parallel ridge pattern and asymmetry of colors and structures

\section{Lentigo maligna melanoma}

Differentiating lentigo maligna melanoma (LMM) from solar lentigo or seborrheic keratosis (SL/SK), pigmented actinic keratosis (PAK) and lichen planuslike keratosis (LPLK) is highly challenging, even with the use of dermoscopy.

Schiffner et al. $(17,18)$ were the first to propose a progression model for LMM that includes four dermoscopic criteria: asymmetrical pigmented follicular openings, dark rhomboidal structures, slate-gray dots forming an annular-granular pattern, and slate-gray globules (Figure 4). The combination of these features showed a sensitivity of $89 \%$ and a specificity of $96 \%$ in the diagnosis of LMM. Furthermore, light brown fingerprint areas and horny pseudocysts were indicated as features representing benign growths.

Later, Pralong et al. (19) studied 125 cases and noted that at least one of the four 4 SchiffnerStolz criteria were present in $87 \%$ of lesions, and further described four additional criteria: mainly vascular - increased density of the vascular network, red rhomboidal structures, target-like patterns and darkening at dermoscopic examination (when compared with naked-eye examination).

Tschandl et al. (20) analyzed dermatoscopy images of 240 flat pigmented facial skin lesions and claimed that a pattern of circles is highly suggestive for LMM, while the presence of gray color strengthens the diagnosis.

Finally, Lallas et al. (21), attempted to differentiate facial LMM from PAK, and conducted a study of 144 lesions with LMM, PAK and SL/SK and created a scoring scheme for LMM diagnosis; a total score of $\geq$ 1 has a sensitivity of $92.9 \%$ and a specificity of $55.4 \%$ for the diagnosis of LMM. Furthermore, the absence of evident follicles (the follicular openings within the pigmented lesion are not clearly visible and obvious and are obscured by pigmentation of any color) in combination with gray rhomboidal lines are suggestive of LMM and biopsy is required.

\section{Nodular melanoma}

Nodular melanoma (NM) is a rapidly progressing neoplasm with a high risk for metastasis, even in its early stages $(22,23)$. NM lacks an initial radial growth phase, presenting with a vertical growth (22). Furthermore, it lacks the commonly used ABCD criteria (asymmetry, border irregularity, color variegation, diameter $\geq 6 \mathrm{~mm}$ ), while, dermoscopically, NM displays no "traditional" melanoma-specific criteria. For these reasons, the EFG 


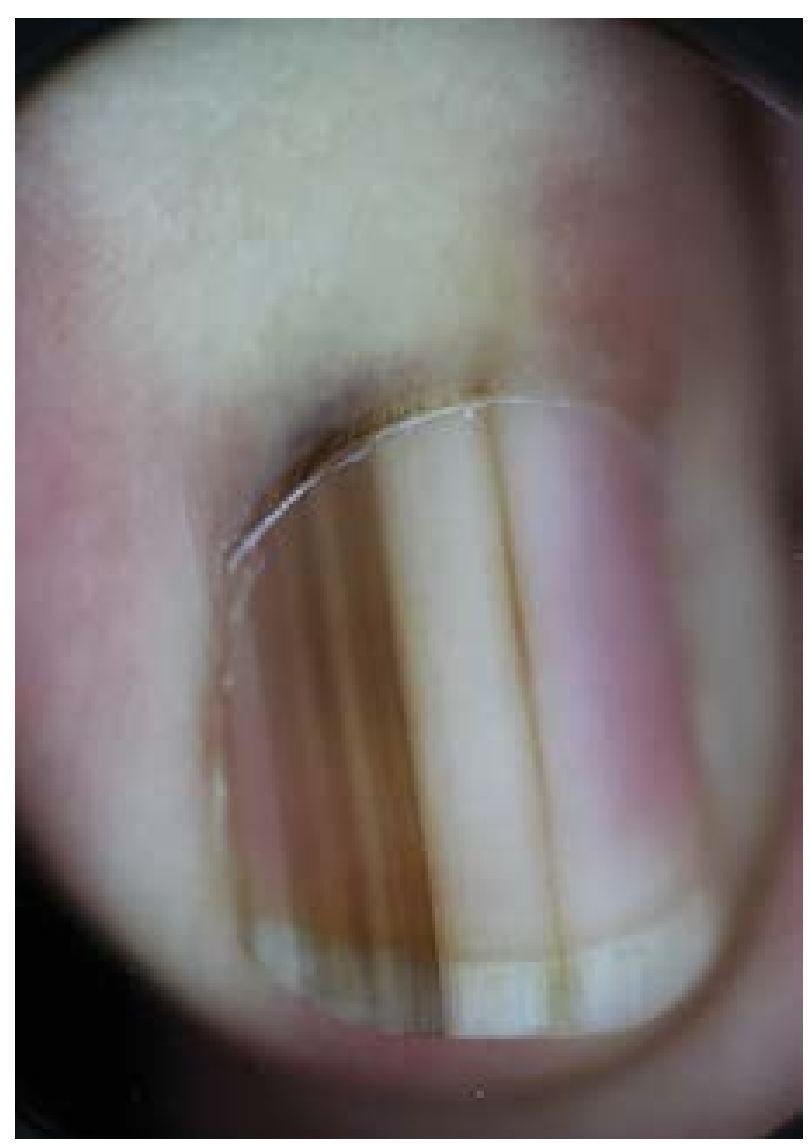

Figure 3. Dermoscopy of a subungual melanoma revealing brown to black longitudinal lines, characterized by irregularity in terms of color, spacing and width. Hutchinson's sign is also evident rule (Elevation, Firmness on palpation, continuous Growth over one month) has been introduced in clinical practice in the diagnosis of NM.

Several studies attempted to examine and propose dermoscopic features for NM recognition. Argenziano et al, (24) proposed the blue-black rule, that is blue (usually structureless) and black (dots, globules, blotches) areas involving at least $10 \%$ of the lesion surface, as a significant indicator of NM. The blue color corresponds to pigmented melanocytes in the deep dermis, while black arises from intraepidermal melanin or from dense dermal proliferation of pigmented melanocytes under a thinned epidermis, usually due to ulceration (25). The combination of the blue-black feature and one or more of the standard melanoma criteria has a $84.6 \%$ sensitivity and $80.5 \%$ specificity.

In 2015, Pizzichetta et al. (5) studied 457 pigmented skin lesions in order to describe dermoscopic characteristics of pigmented NM, compared with SSM and pigmented nodular non melanocytic and benign melanocytic lesions. A multivariate analysis showed that asymmetric pigmentation, blue-black pigmented areas, homogeneous disorganized pattern, a combination of polymorphous vessels and milky red globules/areas or red homogeneous areas, significantly increased the risk of NM (Figure 5). On the other hand, homogeneous pattern was found to be a positive factor for nonmelanocytic and benign melanocytic lesions. Finally, ulcerations, homogeneous disorganized patterns, and homogeneous blue pigmented structureless areas, are features favoring a NM diagnosis, in contrast with peripheral light brown structureless areas which advocate in favor of SSM.

\section{Melanomas in patients with multiple nevi}

It has been demonstrated that dermoscopy is more accurate than naked eye examination for melanoma detection $(26,27)$. However, in patients with multiple atypical nevi, dermoscopy might be inadequate to uncover a melanoma among a plethora of clinically and dermoscopically atypical moles (28).

A high number of melanocytic nevi is considered to be a major risk factor for melanoma $(29,30)$. Given that melanoma can sometimes be misdiagnosed as a nevus, the diagnosis of the malignancy among patients with more than 50 common nevi in total, or multiple clinically 'atypical' or 'dysplastic' moles (referring to diagnostic uncertainty of being a melanoma) is very challenging. Subsequently, early melanoma detection and reduction of unnecessary excisions is of utmost importance. The most effective strategy to manage these patients includes clinical and dermoscopic examination of all lesions, in order to identify the 'signature nevus pattern' of each patient (comparative approach). The comparative approach is based on the observation that the majority of an individual's nevi display similar dermoscopic characteristics, while melanoma deviates this "signature pattern" (31-33). Another suggested strategy for the management of these patients includes the use of digital dermoscopy monitoring of melanocytic lesions, based on the fact that benign lesions stay stable while melanomas change over time (34).

Meta-analytic data of digital dermoscopy followup (DDF) of melanocytic skin lesions (35), suggested that DDF is a reliable method for the detection of early melanomas, while maintaining a reasonably low rate of excisions of benign moles. Specifically, more than half of excised melanomas in patients under DDF were in situ and, among invasive tumors, none was thicker than $1 \mathrm{~mm}$. It was also noted that longer follow-up period was related with the diagnosis of more melanomas. Therefore, one can assume that close surveillance, 


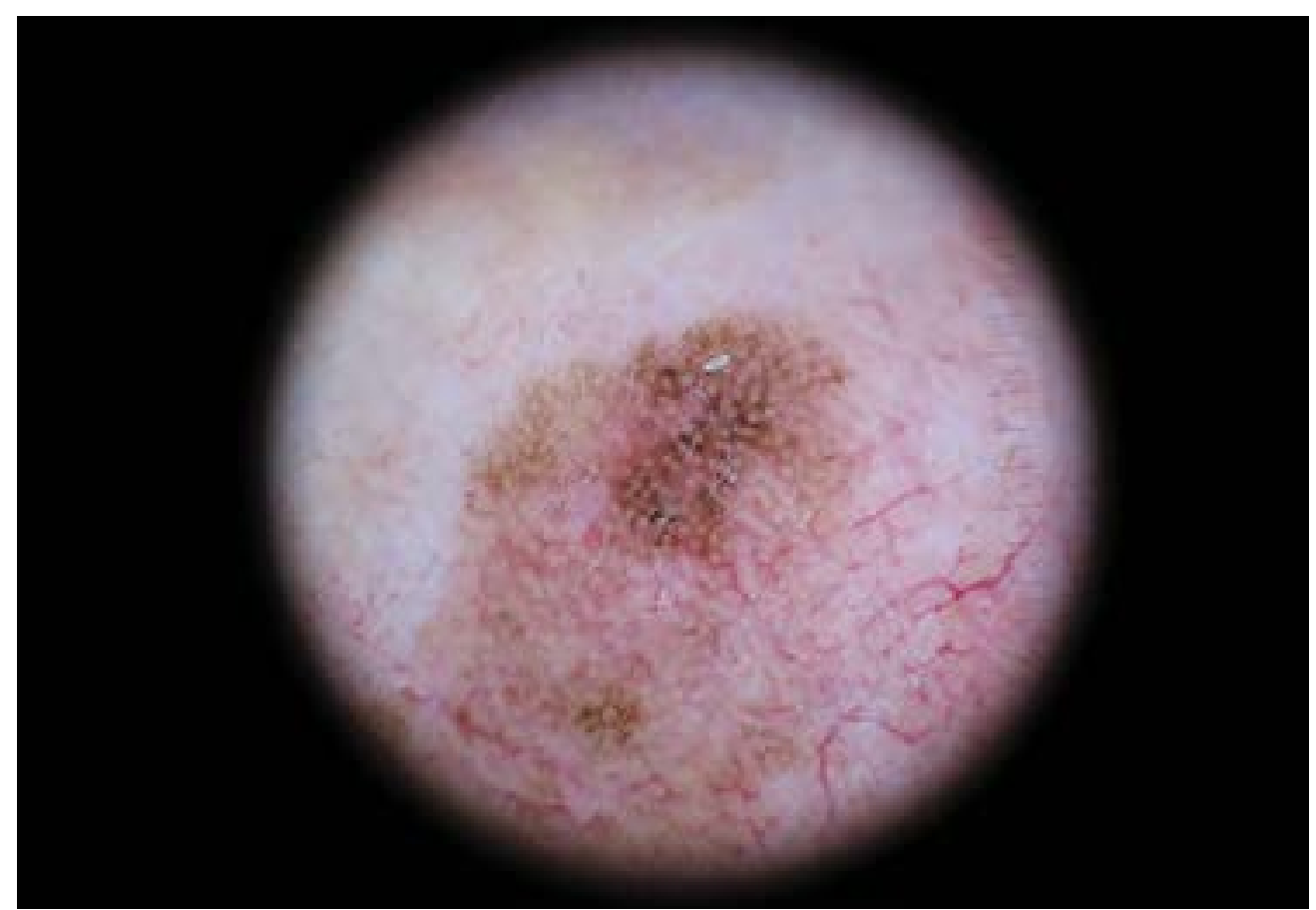

Figure 4. Dermoscopy of an early lentigo maligna characterized by asymmetrically pigmented follicular openings and slate-gray dots and globules

especially of high-risk patients, is mandatory for early diagnosis of the malignancy. Moscarella et al. (36) noted that not only long- but also short-term dermoscopy monitoring is highly effective for melanoma detection in patients with multiple atypical nevi.

The International Dermoscopy Society (37), suggested two different strategies of follow-up based on the number of lesions. When clinicians face a suspicious lesion in a patient with a single or a few lesions, an excision or a 2 to 4 month monitoring period should follow. If the lesion is benign, no further examination is needed. The second strategy is suggested for patients with multiple lesions, where a comparative approach should be first applied (with a possible excision of the most atypical lesion). Consequently, a follow-up (of flat reticular lesions only) should be first scheduled after a 3 -month interval following the baseline visit, and then after a 6-12 month interval. Elevated equivocal lesions with significant regression should not be monitored but excised because of the possibility of being invasive melanomas. Finally, it has to be stated that patients' compliance was found to be optimized by short- rather than long-term intervals between the visits (38).

\section{Conclusion}

Dermoscopy is considered to be an integral part of clinical examination for the evaluation and detection of melanoma. Recent advances in the morphological evaluation of melanomas, changing the "traditional" criteria, enhance recognition of melanomas that might otherwise escape detection. As more studies are performed and new data are gathered, clinicians should always update their knowledge in order to minimize the risk of missing a melanoma.

\section{Abbreviations}

SSM - Superficial spreading melanoma

AM - Acral melanoma

IDS - International Dermoscopy Society

MM - Mucosal melanomas

LMM - Lentigo maligna melanoma

PAK - Pigmented actinic keratosis

LPLK - Lichen planus-like keratosis

NM - Nodular melanoma

ABCD - Asymmetry, border irregularity, color variegation, diameter $\geq 6 \mathrm{~mm}$

EFG -Elevation, Firmness, Growth

DDF - Digital dermoscopy follow-up

\section{References}

1. Russo T, Piccolo V, Lallas A, Argenziano G. Recent advances in dermoscopy. F1000Res. 2016;5.

2. Bowling J, Argenziano G, Azenha A, Bandic J, Bergman R, Blum A, et al. Dermoscopy key points: recommendations from the International Dermoscopy Society. Dermatology. 


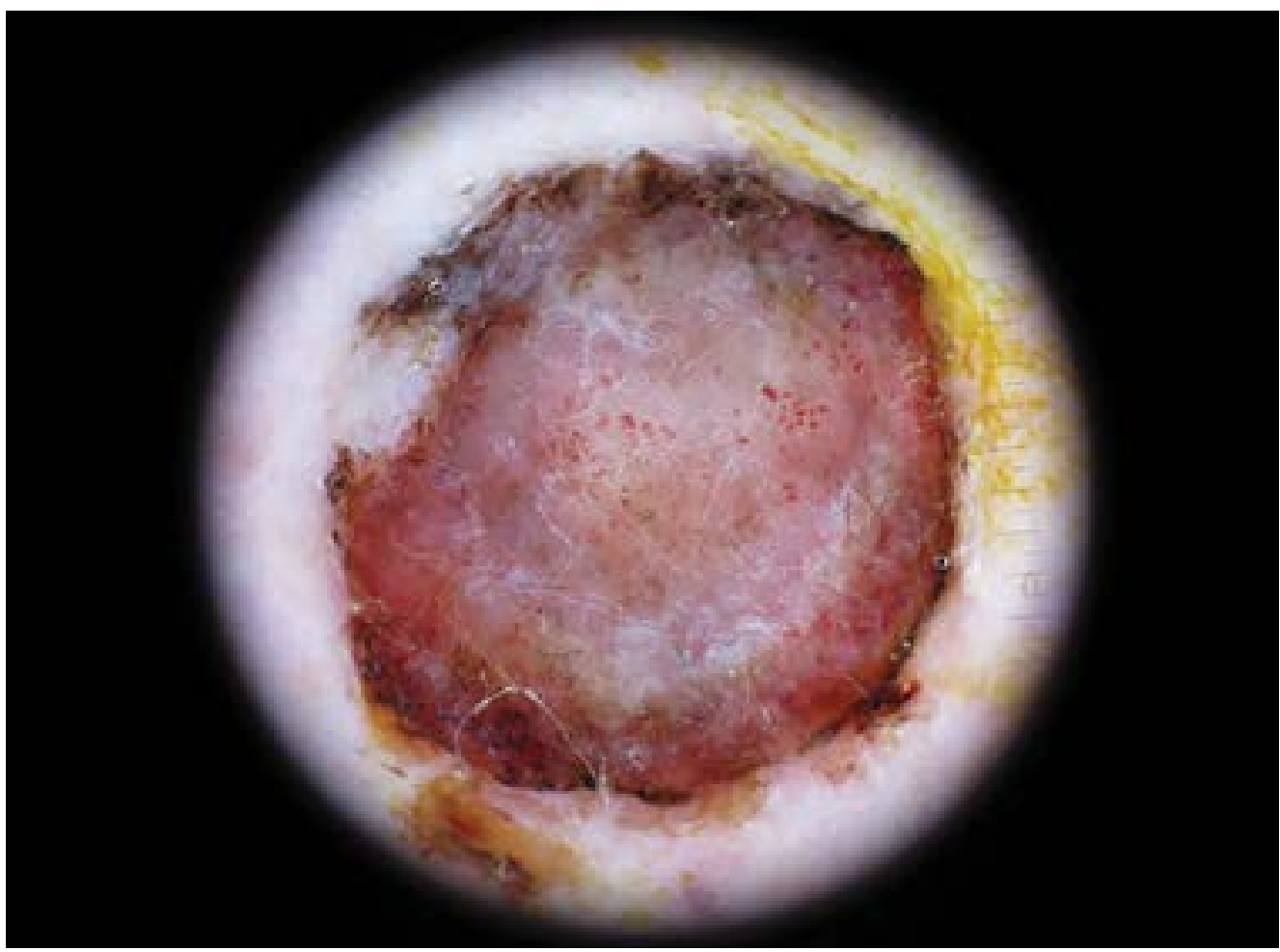

Figure 5. Dermoscopy of an amelanotic nodular melanoma revealing linear, irregular, and tortuous vessels over a milky-red background. Hemorrhages are also evident

2007;214(1):3-5.

3. Sadayasu A, Tanaka M, Maumi Y, Ikeda E, Sawada M, Ishizaki $S$, et al. Abrupt intralesional color change on dermoscopy as a new indicator of early superficial spreading melanoma in a Japanese woman. Case Rep Dermatol. 2015;7(2):123-8.

4. Ciudad-Blanco C, Avilés-Izquierdo JA, Lázaro-Ochaita P, Suárez-Fernández R. Dermoscopic findings for the early detection of melanoma: an analysis of 200 cases. Actas Dermosifiliogr. 2014;105(7):683-93.

5. Pizzichetta MA, Kittler H, Stanganelli I, Bono R, Cavicchini $S$, De Giorgi V, et al. Pigmented nodular melanoma: the predictive value of dermoscopic features using multivariate analysis. Br J Dermatol. 2015;173(1):106-14.

6. Argenziano G, Fabbrocini G, Carli P, De Giorgi V, Delfino M. Epiluminescence microscopy: criteria of cutaneous melanoma progression. J Am Acad Dermatol. 1997;37(1):68-74.

7. Argenziano G, Ferrara G, Francione S, Di Nola K, Martino A, Zalaudek I. Dermoscopy--the ultimate tool for melanoma diagnosis. Semin Cutan Med Surg. 2009;28(3):142-8.

8. Braun RP, Thomas L, Dusza SW, Gaide O, Menzies S, Dalle S, et al. Dermoscopy of acral melanoma: a multicenter study on behalf of the International Dermoscopy Society. Dermatology. 2013;227(4):373-80.

9. Saida T, Ikegawa S, Ishihara K. Relation of maximum diameters of plantar malignant melanoma to various prognostic factors and prognosis of patients. Nihon Hifuka Gakkai Zasshi. 1989;99(11):1167-72.

10.Saida T, Yoshida N, Ikegawa S, Ishihara K, Nakajima T. Clinical guidelines for the early detection of plantar malignant melanoma. J Am Acad Dermatol. 1990;23(1):37-40.
11.Saida T, Ishihara Y, Tokuda Y. Effective detection of plantar malignant melanoma. Int J Dermatol. 1993;32(10):722-5.

12.Phan A, Dalle $S$, Touzet $S$, Ronger-Savlé S, Balme B, Thomas L. Dermoscopic features of acral lentiginous melanoma in a large series of 110 cases in a white population. Br J Dermatol. 2010;162(4):765-71.

13. Di Chiacchio ND, Farias DC, Piraccini BM, Hirata SH, Richert B, Zaiac M, et al. Consensus on melanonychia nail plate dermoscopy. An Bras Dermatol. 2013;88(2):309-13.

14.Lallas A, Kyrgidis A, Koga H, Moscarella E, Tschandl P, Apalla Z, et al. The BRAAFF checklist: a new dermoscopic algorithm for diagnosing acral melanoma. Br J Dermatol. 2015;173(4):1041-9.

15.Lin J, Koga H, Takata M, Saida T. Dermoscopy of pigmented lesions on mucocutaneous junction and mucous membrane. Br J Dermatol. 2009;161(6):1255-61.

16.Blum A, Simionescu O, Argenziano G, Braun R, Cabo H, Eichhorn A, et al. Dermoscopy of pigmented lesions of the mucosa and the mucocutaneous junction: results of a multicenter study by the International Dermoscopy Society (IDS). Arch Dermatol. 2011;147(10):1181-7.

17.Schiffner R, Schiffner-Rohe J, Vogt T, Landthaler M, Wlotzke $U$, Cognetta $A B$, et al. Improvement of early recognition of lentigo maligna using dermatoscopy. J Am Acad Dermatol. 2000;42(1 Pt 1):25-32.

18.Stolz W, Schiffner R, Burgdorf WH. Dermatoscopy for facial pigmented skin lesions. Clin Dermatol. 2002;20(3):276-8.

19.Pralong P, Bathelier E, Dalle S, Poulalhon N, Debarbieux S, Thomas L. Dermoscopy of lentigo maligna melanoma: report of 125 cases. Br J Dermatol. 2012;167(2):280-7. 
20.Tschandl P, Rosendahl C, Kittler H. Dermatoscopy of flat pigmented facial lesions. J Eur Acad Dermatol Venereol. 2015;29(1):120-7.

21. Lallas A, Tschandl P, Kyrgidis A, Stolz W, Rabinovitz H, Cameron A, et al. Dermoscopic clues to differentiate facial lentigo maligna from pigmented actinic keratosis. $\mathrm{Br} \mathrm{J}$ Dermatol. 2016;174(5):1079-85.

22.Clark WH Jr, From L, Bernardino EA, Mihm MC. The histogenesis and biologic behavior of primary human malignant melanomas of the skin. Cancer Res. 1969;29(3):705-27.

23.Ferrara G, Gianotti R, Cavicchini S, Salviato T, Zalaudek I, Argenziano G. Spitz nevus, spitz tumor, and spitzoid melanoma: a comprehensive clinicopathologic overview. Dermatol Clin. 2013;31(4):589-98.

24.Argenziano G, Longo C, Cameron A, Cavicchini S, Gourhant JY, Lallas A, et al. Blue-black rule: a simple dermoscopic clue to recognize pigmented nodular melanoma. $\mathrm{Br} \mathrm{J}$ Dermatol. 2011;165(6):1251-5.

25. Longo C, Farnetani F, Moscarella E, de Pace B, Ciardo S, Ponti G, et al. Can noninvasive imaging tools potentially predict the risk of ulceration in invasive melanomas showing blue and black colors? Melanoma Res. 2013;23(2):125-31.

26.Bafounta ML, Beauchet A, Aegerter P, Saiag P. Is dermoscopy (epiluminescence microscopy) useful for the diagnosis of melanoma? Results of a meta-analysis using techniques adapted to the evaluation of diagnostic tests. Arch Dermatol. 2001;137(10):1343-50.

27.Vestergaard ME, Macaskill P, Holt PE, Menzies SW. Dermoscopy compared with naked eye examination for the diagnosis of primary melanoma: a meta-analysis of studies performed in a clinical setting. $\mathrm{Br} \mathrm{J}$ Dermatol. 2008;159(3):669-76.

28. Puig S, Argenziano G, Zalaudek I, Ferrara G, Palou J, Massi $\mathrm{D}$, et al. Melanomas that failed dermoscopic detection: a combined clinicodermoscopic approach for not missing melanoma. Dermatol Surg. 2007;33(10):1262-73.

29. Gandini S, Sera F, Cattaruzza MS, Pasquini P, Abeni D, Boyle $\mathrm{P}$, et al. Meta-analysis of risk factors for cutaneous melanoma: I.
Common and atypical naevi. Eur J Cancer. 2005;41(1):28-44.

30.Greene MH, Clark WH Jr, Tucker MA, Kraemer KH, Elder DE, Fraser MC. High risk of malignant melanoma in melanoma-prone families with dysplastic nevi. Ann Intern Med. 1985;102(4):458-65.

31.Grob JJ, Bonerandi JJ. The 'ugly duckling' sign: identification of the common characteristics of nevi in an individual as a basis for melanoma screening. Arch Dermatol. 1998;134(1):103-4.

32.Scope A, Burroni M, Agero AL, Benvenuto-Andrade C, Dusza SW, Rubegni P, et al. Predominant dermoscopic patterns observed among nevi. J Cutan Med Surg. 2006;10(4):170-4.

33.Argenziano G, Catricalà C, Ardigo M, Buccini P, De Simone P, Eibenschutz L, et al. Dermoscopy of patients with multiple nevi: improved management recommendations using a comparative diagnostic approach. Arch Dermatol. 2011;147(1):46-9.

34.Stolz W, Schiffner R, Pillet L, Vogt T, Harms H, SchindewolfT, et al. Improvement of monitoring of melanocytic skin lesions with the use of a computerized acquisition and surveillance unit with a skin surface microscopic television camera. J Am Acad Dermatol. 1996;35(2 Pt 1):202-7.

35. Salerni G, Terán T, Puig S, Malvehy J, Zalaudek I, Argenziano G, et al. Meta-analysis of digital dermoscopy follow-up of melanocytic skin lesions: a study on behalf of the International Dermoscopy Society. J Eur Acad Dermatol Venereol. 2013;27(7):805-14.

36. Moscarella E, Tion I, Zalaudek I, Lallas A, Kyrgidis A, Longo C, et al. Both short-term and long-term dermoscopy monitoring is useful in detecting melanoma in patients with multiple atypical nevi. J Eur Acad Dermatol Venereol. 2016 Jul 16.

37.Argenziano G, Giacomel J, Zalaudek I, Blum A, Braun RP, Cabo $\mathrm{H}$, et al. A clinico-dermoscopic approach for skin cancer screening: recommendations involving a survey of the International Dermoscopy Society. Dermatol Clin. 2013;31(4):525-34.

38.Argenziano G, Mordente I, Ferrara G, Sgambato A, Annese P, Zalaudek I. Dermoscopic monitoring of melanocytic skin lesions: clinical outcome and patient compliance vary according to follow-up protocols. Br J Dermatol. 2008;159(2):331-6.

\section{Dermoskopija melanoma s otežanom dijagnostikom}

\section{Sažetak}

Dermoskopija je neinvazivna procedura koja omogućava procenu kožnih lezija i predstavlja korisnu metodu koja značajno unapređuje tačnost $\mathrm{u}$ dijagnostici melanoma. Postoje brojni dermoskopski kriterijumi za melanome, kao i nekoliko algoritama kreiranih za detekciju melanoma. Međutim, prepoznavanje nekih melanoma i dalje je izazov. Melanomi koji nastaju na specifičnim delovima tela, melanomi kod pacijenata sa brojnim netipičnim mladežima i nodularni melanomi, spadaju u podvrste melanoma, jer obično nemaju „klasične“ specifične kriterijume melanoma. Ovaj rad se bavi novijim informacijama o dermoskopiji melanoma teških za dijagnozu sumirajući najnovije podatke. $\mathrm{Na}$ kraju, izdvajamo značaj digitalne dermoskopije u praćenju melanocitnih lezija za otkrivanje početnih melanoma uz održavanje niske stope ekcizija.

\section{Ključne reči}

Dermoskopija; Melanom; Dijagnoza; Kožne neoplazme 